\title{
El papel de la solidaridad en el fundamento del Derecho Tributario: análisis de la solución de reconciliación propuesta por Francisco Saffie en la racionalidad de los impuestos y la idea de reciprocidad frente a la noción de ciudadanía fiscal
}

The Role of Solidarity in the Foundation of Tax Law: An Analysis of the Reconciliation Solution Proposed by Francisco Saffie in the Rationality of Taxes and the Idea of Reciprocity Against the Notion of Fiscal Citizenship

Eurico Marcos Diniz de Santi*

Recepción: 28/08/19

Evaluación: 28/08/19

Aceptación final: 29/08/19

Resumen: Este artículo explora la idea de propiedad por medio de la tributación, frente a la simplicidad, transparencia, ciudadanía fiscal, reforma tributaria, defendiendo la noción de reciprocidad en los impuestos.

Palabras clave: propiedad, tributación, simplicidad, transparencia, ciudadanía fiscal, reforma tributaria y reciprocidad tributaria.

Máster y Doctorado en Derecho Tributario por la Pontifícia Universidade Católica de São Paulo, Brasil. Profesor de la Escola de Direito de São Paulo da Fundaçao Getulio Vargas, Brasil. Director del Centro de Ciudadanía Fiscal-CCiF. Correo electrónico: eurico.santi@fgv.br 


\begin{abstract}
This article explores the idea of property through taxation, in light of simplicity, transparency, fiscal citizenship, tax reform and provides the notion of reciprocity in taxation.
\end{abstract}

Keywords: property, taxation, simplicity, transparency, fiscal citizenship, tax reform and tax reciprocity.

\title{
1. Introducción
}

El punto central de este ensayo es debatir los esbozos construidos por Francisco Saffie en su artículo sobre la racionalidad de los impuestos, en el cual analiza los problemas existentes en el derecho tributario contemporáneo, critica algunas soluciones sugeridas y, finalmente, construye una propuesta alternativa basada en la solidaridad como práctica. La idea principal del autor es deconstruir la noción que denomina el paradigma clásico del derecho tributario, basado en la noción de propiedad privada versus impuestos como propiedad privada justificada por la tributación.

Inspirados en Saffie, analizaremos qué elementos deben observarse para apoyar la idea de propiedad mediante la solidaridad, a través de tres conceptos: simplicidad, transparencia y ejercicio de la ciudadanía fiscal, como instrumentos para superar la alienación y las deformidades de la legalidad que marcan los problemas de la tributación en Brasil, sugiriendo la proyección de la narrativa consagrada de la solidaridad en dirección a la reciprocidad. Los desafíos de Brasil preceden a la noción de solidaridad. La complejidad del sistema brasilero donde tres entes federativos (Unión, 27 Estados y 5670 Municipios) detentan competencias impositivas propias, obliga que el contribuyente interprete millones de legislaciones dispersas y desarticuladas, fomentando la industria del litigio que flexibiliza la legalidad y disemina la inseguridad jurídica.

La relación entre fisco y contribuyente está marcada por el distanciamiento y por la desconfianza mutua entre las partes y se revela en una estructura derivada del Patrimonialismo de Estado Portugués, muy bien resumida por Otto Mayer: el derecho constitucional pasa, el derecho administrativo (tributario) permanece.

En ese escenario kafkiano, el manto de la solidaridad funciona como un telón para ocultar la ineficiencia e irresponsabilidad fiscal del Estado brasi- 
El papel de la solidaridad en el fundamento del Derecho Tributario: ...

lero que encubre la máxima "no taxation without representation", mediante la confusión teórica entre contribuyente de hecho y contribuyente de derecho, ocultando la promiscua relación política entre las tres esferas estatales y 20 millones de empresas que, además de nefasta, aleja 200 millones de ciudadanos del debate informado y democrático sobre la carga tributaria y el tamaño de Estado que debería tener lugar en las elecciones.

La tributación se justifica por la primacía de que la convivencia en sociedad exige costos necesarios para el mantenimiento del Estado y que esta idea incluye tanto el ejercicio del derecho de propiedad como la justificación de la tributación por la idea de solidaridad social ${ }^{1}$. En Brasil, actualmente, tales derechos a la propiedad y a la tributación (con apoyo en la solidaridad) están siendo utilizados para justificar posiciones antagónicas: sea por parte del contribuyente que maneja la ley para obtener exenciones o que realiza evasión para pagar menos impuestos, sea por parte del gobierno que flexibiliza la legalidad usando la máquina fiscal con el objetivo obsesivo de recaudar más y manipular privilegios (Santi, 2014).

El estudio de las formas lógicas demostró ser un panóptico, una arquitectura jurídica de poder informada por la ausencia de transparencia de la legalidad concreta y de las prácticas de las autoridades fiscales: no hay fórmulas legales, sino estructuras que se ajustan al concepto de "derecho", gozan de la presunción de "validez" y que, no obstante, generan injusticia e inseguridad jurídica (Santi, 2014, p. 30).

\section{Los movimientos de Saffie}

Francisco Saffie en su artículo titulado "La racionalidad de los impuestos" señala que el derecho tributario atraviesa por dos tipos de problemas. Uno primero de verificación o legitimidad de la institución, que se presenta en la justificación de los tributos frente a un mundo gobernado por políticas económicas neoliberales. Un segundo problema de aplicación, en que la idea de

1 Vea mi discurso en el evento realizado con representantes de la Receta Federal del Brasil en el evento denominado "Nova Receita Federal Do Século XXI: eficiência, responsabilidade e accountability”. Disponible en: https://youtu.be/skK9yH0ZVpY 
un sistema tributario con igualdad económica se muestra ineficiente por aplicación de estrategias de evasión y elusión tributarias por los contribuyentes.

Frente a tales problemas, el autor hace un diagnóstico actual del Derecho Tributario, critica algunas soluciones propuestas para solucionar estos dos problemas, puesto que ellas no dan cuenta de la realidad subyacente de esta área jurídica (una visión eminentemente instrumental) y propone una nueva evaluación de que los impuestos son una práctica de "vida ética y es esencial para la solidaridad" que justifica la existencia en un Estado Moderno garante de la propiedad.

\subsection{La identificación de los problemas de legitimidad del derecho tributario}

Para el autor, los impuestos poseen la finalidad de redistribución y financiamiento de los gastos públicos, basado en un ideal de igualdad que se presenta como pilar de los sistemas políticos democráticos. Considera que tales finalidades vienen siendo dejadas de lado por dos motivos: (i) un discurso que pone en duda la legitimidad de la redistribución política y económica de carácter inmediata; (ii) la insuficiencia del Derecho Tributario para materializar las consecuencias legales que debería tener con respecto a la recaudación, este con carácter jurídico inmediato, pero también político y económico mediato.

En lo relativo a legitimidad de la redistribución, presenta los problemas derivados del carácter económico. Según el autor, la legitimidad fue atacada desde este punto de vista, frente a la sensación de falta de retribución (pago de los impuestos y falta de prestaciones públicas), visión de que los recursos provienen única y exclusivamente de los dueños del capital, de la dicotomía de límites entre los impuestos y la propiedad privada, entendiéndose a esta última como un derecho natural, y del fracaso del capitalismo democrático (redistributivo) verificado en la evolución de la política económica de los Estados sucedida en los últimos cuarenta años ${ }^{2}$, bien como un cambio en

2 En aquello que se denominó, con base en Streeck, "proceso de des-democratización del capitalismo a través de la des-economización de la democracia”, sobre dos factores: (i) nivel local, disminución del gasto público verificado en políticas de austeridad, disminución de 
El papel de la solidaridad en el fundamento del Derecho Tributario: ...

el modelo económico verificado en la exención del capital privado, la desafectación tributaria de la realización de políticas públicas, con su ejecución por medio de la deuda pública, que se presentó acumulada.

Los problemas sobre este carácter también se presentan por la disparidad existente entre el discurso neoliberal defendido y practicado. Los defensores de las políticas neoliberales argumentan que han mejorado la calidad de vida de las personas en el mundo, principalmente en los países en desarrollo, dado el mayor acceso a los productos y bienes, con un sistema de información que permite la distribución eficiente de recursos.

Sin embargo, la divergencia presentada por Colin Crouch demuestra que la utilización de la política neoliberal produce concentración de poder en empresas multinacionales, que actúan de manera exitosa, por medio de lobby, en el resguardo de sus intereses y evidencian el poder de la riqueza privada sobre la política: mayor desigualdad económica que conduce a una mayor desigualdad política. Estas empresas, en su opinión, son las que realmente se benefician de la libertad económica del neoliberalismo.

Hay una concentración de capital en aquellos que ya poseen su dominio, principalmente por la baja carga tributaria que obtienen: a su vez, frente al mantenimiento de los gastos públicos, la carga de este escenario de exención es soportado preponderantemente por la clase media por medio de los impuestos indirectos. Son estos efectos notados por las políticas neoliberales que causan el problema de legitimidad del sistema tributario.

Con respecto al sentido político, basado en Wendy Brown, el autor afirma que la idea normativa del neoliberalismo entiende a los individuos como unidades de capital humano que compiten entre sí frente a una noción liberal del contrato social, situación que destruye la noción de solidaridad y que justifica los sistemas tributarios progresivos.

En esta perspectiva, el neoliberalismo entraría en conflicto con la solidaridad y este conflicto tiene el poder político de impactar en la legitimidad y en la insuficiencia del Derecho Tributario para lograr sus objetivos con respecto a la recaudación.

la carga tributaria del capital y de los mercados financieros y privatización de los servicios públicos; (ii) nivel global, especialmente en Europa, estructura de integración internación que dificultaron más la toma de decisión mediante procedimientos democráticos. 


\subsection{Una reconstrucción teórica del estado actual del derecho tributario. El paradigma clásico}

Saffie entiende que los problemas de legitimidad del derecho tributario residen en los presupuestos por los cuales se construye el diseño institucional del derecho tributario actual, dado que se apropia de una relación entre propiedad privada e impuestos, útil para las políticas neoliberales.

De acuerdo con el paradigma clásico, los impuestos solo se justifican con el consentimiento de los individuos y de sus intereses individuales, siendo así medios para un fin a favor de la sociedad civil. Este paradigma se construye sobre tres elementos: (i) los impuestos se justificarían como instrumentos para la recaudación fiscal; (ii) una concepción de los individuos como seres puramente racionales; y (iii) de acuerdo con una concepción de la propiedad privada como derecho natural, opuesto a los impuestos.

El autor describe la definición dada a los impuestos por Seligman, como medios económicos que el gobierno puede obtener coercitivamente de los contribuyentes para el financiamiento de sus actividades, esto es, gastos de interés común de todos. De esta forma, el carácter obligatorio se justifica en virtud de un beneficio directo y común para los individuos.

Hobbes, en su obra Leviatán, refiere que la justificación de los impuestos se da en el hecho de que proporciona los medios económicos necesarios que permiten al representante soberano cumplir sus funciones. Locke da la misma justificación instrumental de la tributación, en Second Treatise of Government, en que los impuestos deben ser pagados para que el gobierno pueda dar protección a los derechos naturales de los individuos y también por Rawls, que caracteriza los tributos con dos funciones distintas, la correctiva y la distributiva. Los tres autores definen los impuestos como una forma instrumental de alcanzar los beneficios directos de los individuos que firman el contrato social.

El segundo elemento que compone el paradigma clásico se refiere a la naturaleza de las personas. Según esta concepción, los individuos son seres puramente racionales, con cierto estatus moral y portadores de derechos, los que se caracterizan por tener un razonamiento instrumental en relación a los fines que consideran valiosos, guiados por su propio interés. Por lo tanto, la autoridad y la validez de las normas, morales o jurídicas, dependen 
El papel de la solidaridad en el fundamento del Derecho Tributario: ...

de si operan de acuerdo con la racionalidad humana, ya que solo se cumplirán si se consideran racionales y en interés de los individuos.

El tercer elemento corresponde a la idea de que la propiedad privada es un derecho natural. Esta concepción tuvo origen en el siglo XVII en las teorías contractualistas del Estado, el que tiene la función de proteger los derechos naturales de las personas. Nozick, siguiendo la comprensión común de las teorías liberales de la justicia, entiende que los impuestos son pagos voluntarios para financiar las actividades que los individuos destinan al Estado mínimo. Según Saffie, Nozick al aplicar esta idea requiere una justificación para el pago de los tributos, ya que de lo contrario sería equivalente a un "robo coercitivo del Estado" invasivo del derecho natural.

Saffie afirma que este paradigma clásico del derecho tributario dio origen a la forma institucional del derecho tributario actual, el cual se sistematiza a partir de su teoría general: el deber jurídico del contribuyente de pagar impuestos tiene un derecho correlativo, la pretensión del Estado de cobrarlos.

La relación entre el Estado y el contribuyente transforma la obligación tributaria en una relación jurídica, en la cual el hecho imponible representa la voluntad del Estado. Dicha estructura es, en opinión del autor, un límite para la interpretación analógica de la función del derecho tributario, ya que sin la satisfacción del hecho imponible por el contribuyente, no existe obligación legal de pagar impuestos. Por lo tanto, dicha obligación se encuentra en desventaja en relación a la protección de la propiedad privada (propiedad privada versus tributación).

En la perspectiva de Saffie, son dos las propuestas para solucionar el paradigma clásico y ambas son insuficientes. La primera es la justificación liberal igualitaria de los impuestos y la segunda es la idea de una legislación basada en principios.

\subsection{La justificación liberal igualitaria de los impuestos}

Saffie explica que la tradición liberal igualitaria, relatada por Murphy y Nagel en la obra The Myth of Ownership, considera asumir la justicia de los sistemas tributarios como asunto político e independiente del principal problema en las discusiones sobre justicia y política tributaria. Establecer 
un principio de justicia para determinar cuánto debe pagar cada contribuyente y cuántos recursos transfiere el gobierno a cada uno, no es suficiente. Se debe considerar cada sistema económico en su totalidad, con miras a la recaudación y a los gastos públicos.

Asumir que la distribución del mercado es justa, independientemente de los efectos de los impuestos y del sistema convencional de los derechos, como lo hace el patrimonio tributario, es llamado por ellos "libertarismo de cada día", y abandonarlo significa entender la propiedad privada como un derecho convencional, definido por un complejo esquema de reglas, entre las cuales se incluyen los impuestos, que se justifican de acuerdo con una determinada teoría de justicia.

Saffie concluye, por lo tanto, en que no se puede discutir sobre la justicia antes o después de los impuestos, teniendo la concepción de que la justicia distributiva retoma la discusión acerca de la tributación y de la propiedad privada. Por lo tanto, los sistemas tributarios poseen dos funciones principales: (i) definir la división entre público y privado y, (ii) determinar la distribución del producto social entre propiedad privada y bienes públicos.

\subsection{Una alternativa: entender que la legislación tributaria se construye sobre principios jurídicos}

Saffie afirma que la alternativa más relevante presentada para superar los problemas del derecho tributario basados en las limitaciones de la teoría de la obligación tributaria general es la sustitución de la estructura de reglas por una de principios, en los términos propuestos por Judith Freedman. Esta alternativa sería suficiente para descartar los casos de elusión tributaria que se apoyan en reglas bajo la justificación de que la tributación no estaría allí prevista.

Como Saffie señala, Freedman defiende que una legislación basada en principios sería suficiente para captar la necesaria intención del legislador y cuando esta no quedase expuesta de manera clara, podría presentarse como una guía con criterios de cómo localizar dicha voluntad. Así sería posible distinguir la intención de la ley-elementos accesorios presentados por el legislador- de la voluntad de la ley-elementos que se atribuyen a la ley frente al proceso de interpretación. 
El papel de la solidaridad en el fundamento del Derecho Tributario: ...

En este sentido, la utilización de una legislación basada en principios dejaría en claro cuál era la sustancia basada en la voluntad del legislador, sin que sea posible al contribuyente rebelarse contra ésta frente a una justificación jurídica en sustitución a una obligación moral. Este tipo de legislación no sería una legislación finalista, sino una que establecería principios y criterios claros para la decisión del legislador, generando un deber particular y concreto de pagar impuestos.

Saffie critica esta solución por entender que el análisis del derecho tributario sobre una cuestión principialista lo convierte en una categoría vacía, ya que no tendrá un contenido sustantivo (a pesar de prometer uno), además de poner en peligro la idea de legislación y aplicación, causando dos consecuencias: mantenimiento de la falta de legitimidad y falta de comprensión entre la forma y la sustancia; no hay un derecho tributario que pueda ser aplicado al caso particular, a no ser por medio de una legislación específica.

La crítica final a esta teoría es que carece de utilidad para resolver el paradigma clásico. En conclusión del autor, el problema de la insuficiencia del Derecho Tributario para cumplir sus consecuencias de recaudación se basa en el paradigma clásico, existiendo una interdependencia de ambos, lo que justifica, de hecho, apuntar a tal solución primero y con esto una solución de ambos problemas.

\subsection{Una reconstrucción alternativa de la racionalidad del derecho tributario en líneas de la filosofía del derecho de Hegel}

Saffie señala la necesidad de redefinir el paradigma clásico, promoviendo una racionalidad sustantiva distinta de la instrumental existente. Para esto, señala que la mejor comprensión del derecho tributario supone entenderlo como la forma institucional de una práctica con un bien interno: el reconocimiento recíproco.

Con fundamento en Alasdair MacIntyre, afirma que una práctica consiste en una actividad humana cooperativa, establecida socialmente, mediante la cual se realizan los bienes inherentes a la misma mientras se intenta lograr los modelos de excelencia individual. El bien interno se 
presenta cuando una persona realiza una práctica con interés propio para los fines que presenta, a diferencia de los bienes externos, que son justificaciones distintas de la realización de una acción determinada por sí misma.

Las prácticas, en opinión del autor, también se diferencian de las instituciones. Mientras que las prácticas se refieren al bien interno, las instituciones se refieren a los bienes externos. Esta diferencia estaría basada en un ideal de virtud (bien interno) frente a un ideal de bienes materiales y poder (bien externo). Sin embargo, ambos están estrechamente relacionados, ya que los bienes internos solo se sostienen a lo largo del tiempo cuando están conectados a los bienes externos. Por lo tanto, existe una relación directa entre los bienes internos y los bienes externos (prácticas de las instituciones), una relación de justificación.

Frente a esta constatación, Saffie afirma que la idea de Hegel sobre individuos y comunidad política es relevante para verificar el bien interno en una práctica. En su opinión, solamente existirá un individuo cuando éste sea considerado ante una comunidad política: surge la posibilidad de reconciliar la antigua idea de comunidad ética con la noción moderna de individuo.

En este intento de reconciliación el autor trabaja dos puntos: primero aborda la noción de individuo frente a la idea de reconocimiento; $y$, frente a esta noción, señala una relación entre tributación y reconocimiento.

La idea de reconocimiento siempre estará ligada con una interacción obtenida en el entorno social ${ }^{3}$. Las prácticas e instituciones estarán vinculadas en esta perspectiva frente a las ideas de derecho y solidaridad, vinculación que, en su opinión, es negada por el concepto instrumental de los tributos planteado en el neoliberalismo.

La conclusión principal de Saffie es que los sistemas tributarios pueden ser considerados como una práctica a partir de la cual se puede aprender sobre la virtud de la dependencia mutua. Frente a dicha constatación, el autor busca defender la idea de que la propiedad privada y los impuestos

3 Como se sostiene, tenemos esferas de reconocimiento que se dividen en etapas (individuo, persona y sujeto), distintos modos (familia, sociedad civil y Estado) y diversos contenidos (relación afectiva, personalidad jurídica abstracta e idea de particularidad individual de realización universal por medio de la solidaridad). 
El papel de la solidaridad en el fundamento del Derecho Tributario: ...

son conceptos inseparables, dos caras de una misma moneda, apartando la idea de derecho natural de la propiedad. Esto se debe a que los impuestos son los medios para subsidiar al Estado, que a su vez, garantiza el espacio de libertad y la propiedad para todos.

Tal conclusión lleva a otras dos conclusiones. Primero, la innecesaria justificación de la redistribución: lo que surge como redistribución es una consecuencia necesaria de un derecho universal de propiedad privada, siendo el derecho tributario como expresión de la solidaridad. Segundo, la obligación de pagar impuestos puede justificarse con nuevos fundamentos, que ya no dependen más de la voluntad de los individuos, sino de un desdoblamiento del derecho de propiedad.

\section{Propiedad, solidaridad y el sistema tributario}

En Brasil, Petronio Baptista de Araújo, en 1954, ya daba cuenta que "la obligación tributaria y el derecho de propiedad son elementos interdependientes, ya que la propiedad individual es garantizada precisamente con los medios de los que el Estado dispone, obtenidos a través de la contribución de sus jurisdicciones" (Jamur, 2005, p. 94).

Más recientemente este punto de vista también fue presentado por Gilmar Ferreira Mendes, aclarando que la "tributación presupone la propiedad privada" de modo que un Estado fundado en la necesidad de ingresos tributarios es, ante todo, un Estado que protege la propiedad privada, siendo el impuesto la fuente primaria de los ingresos públicos para el sostenimiento del Estado y de sus funciones erigidas en la carta magna brasilera (Mendez, 2018, p. 1540).

En el derecho en general esta noción puede ser vista en las obras de Ihering, que ya desarrollaba la idea de que la propiedad solamente podía tener lugar en un contexto de sociedad, que a su vez tiene como génesis la solidaridad (Pereyra, 2007, p. 6).

Esta noción sigue siendo contemporánea, principalmente frente a los problemas de legitimidad de la institución del impuesto y el incumplimiento de las obligaciones tributarias, situaciones que atacan las finalidades 
de redistribución y financiamiento de los gastos públicos frente al ideal de igualdad, como indica Saffie.

Aún si tomáramos esta premisa de que el paradigma clásico retratado se muestra equivocado y que la propiedad y la tributación son dos caras de una misma moneda, todavía queda la cuestión de cómo alcanzar esta visión en la sociedad de modo de presentar el enforcement para la legitimidad y el pago del tributo.

Como dije en la introducción del presente trabajo, los desafíos de Brasil preceden la noción de solidaridad, principalmente frente a una herencia del Patrimonialismo de Estado Portugués que puede ser muy bien resumida por Otto Mayer: el derecho constitucional pasa, el derecho administrativo (tributario) permanece.

Para que se tenga una idea, la legislación constitucional brasilera estipuló que la propiedad no es un derecho absoluto y que deberá cumplir con la función social (art. $5^{\circ}$, XXIII) y frente a esta dirección principialista estableció una vinculación directa entre propiedad y tributación cuando verificado que la propiedad no cumple con esta función, establece un impuesto progresivo en el tiempo (art. 182, $\$ 4^{\circ}$, II). Incluso con esta relación- propiedad/ solidaridad- de manera explícita, los problemas de legitimidad y de cumplimiento de la obligación tributaria también subsisten en Brasil.

Ideas como la complejidad del sistema tributario y la ocultación de ineficiencias e irresponsabilidad apartan al ciudadano del debate sobre la tributación. Tomando la premisa de que la propiedad se da por la tributación, con apoyo en la solidaridad, ¿cuál será la gradación de una o de otra para tener un equilibrio posible que permita la existencia de legitimidad tributaria y cumplimiento de las obligaciones tributarias? Y más que eso, ¿las constataciones en este plano genérico resuelven el problema de la legitimidad y del cumplimiento de la obligación tributaria?.

Incluso si el ciudadano comprendiera que necesita pagar impuestos para vivir en sociedad frente a su carácter redistributivo y de la necesidad del financiamiento de los gastos públicos, aun así tendremos que saber cuál es la carga tributaria que debe pagar y si hay opciones lícitas, si es posible elegir la carga tributaria, así como el modo de recaudar los impuestos a las arcas públicas. La falta de legitimidad puede estar en un punto diferente, como por ejemplo, en una carga tributaria excesiva o, frente a una variedad 
El papel de la solidaridad en el fundamento del Derecho Tributario: ...

de cargas tributarias, una de ellas le sea impuesta una de ellas cuando el contribuyente tenía otra opción.

Esta idea de (i) propiedad versus tributación o (ii) propiedad (sociedad) por medio de la tributación está en la esencia de la historia del Derecho Tributario, en la cual se constató la evolución de un Estado Patrimonial a un Estado del siglo XXI, pasando por un Estado Democrático de Derecho. En el estadio actual, no es posible seguir hablando de una tributación exacerbada para el mantenimiento de la dignidad de todos dentro del grupo social. Dicha afirmación tiene lugar en un contexto de demanda interminable por recursos para que el Estado cumpla los objetivos contenidos en las constituciones ${ }^{4}$.

Pero ella no se muestra aislada. La falta de legitimidad puede estar apoyada, en algunos países, no en el pago del impuesto, sino en la falta de comprensión del sistema tributario o en la identificación de que no hay redistribución, y que el financiamiento de los gastos públicos se realiza con una gran dosis de ineficiencia. En Brasil, por ejemplo, hemos visto situaciones económicas y sociales que alejan o mitigan los ideales de solidaridad.

El sistema tributario es hipercomplejo ${ }^{5}$, diversos y sucesivos escándalos de corrupción, errores de gestión de los asuntos públicos y falta de prestación de servicios públicos básicos que el Estado se propone desarrollar, como salud, educación y seguridad, los cuales también tienen una perspectiva redistributiva, impulsan la disminución del vector de la solidaridad, así considerada la transferencia de riqueza al Estado, y causan un aumento del vector de preservación de la propiedad privada (Gonçalves, 2002, p. 76).

Los datos demuestran que desde los años 90 se tiene la idea de que el Estado no posee más condiciones para administrar la redistribución y el financiamiento del gasto público frente a la clara ineficiencia, con una gra-

4 Para una noción completa de esta idea véase Shoueri, L. E. (2017).

5 Appy, B. et al (2019a). El problema de la gran complejidad del sistema tributario se presenta en un primer momento por la cantidad de legislaciones existentes, para tener una idea, en lo relativo a la tributación sobre el consumo de competencia exclusiva de los Estados Federados podemos llegar a tener 8.790.120 sistemas que se entrelazan. Ver: Arquitetura da destruição: o ICMS e seus 8.709.120 sistemas Disponible en: https://www.jota.info/ opiniao-e-analise/artigos/arquitetura-da-destruicao-o-icms-e-seus-8-709-120-siste-

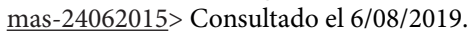


dual y constante alteración de funciones y recursos públicos para los entes privados, como organizaciones no gubernamentales (Jamur, 2005, p. 491).

Esto quiere decir que la centralización de aquello que en otros tiempos se tuvo como el mantenedor de un estatus social que giraba alrededor de la propiedad, y por eso necesitaba de recursos, hoy se presenta como un ideal de limitación estatal y mayor preservación del patrimonio en la mano del particular para que este pueda desarrollar su entorno frente a la libre iniciativa.

Frente a este escenario, considero que la defensa del ideal de asistencia mutua basado en la primacía de la solidaridad estrechamente ligado en la propiedad no es suficiente para solucionar los problemas de legitimidad y cumplimiento de las obligaciones tributarias, a pesar de ser necesario. Esto se debe a que, como bien expresa José Casalta Nabais, esta idea de solidaridad como rescate de un principio del estado social capaz de justificar la legitimidad y cumplimiento de las obligaciones del Derecho Tributario casi siempre implica una mayor expansión e intensificación de la tributación más que su limitación (Nabais, 2015, p. 575).

El impuesto sobre productos industrializados (IPI) es un ejemplo de esta realidad. No obstante, su legislación ha sufrido pocas alteraciones desde su establecimiento en 1960, se observan cambios de criterios en su aplicación para mantener su recaudación. El proceso de desindustrialización prematuro brasilero, iniciado en los años 80 , demuestra una pérdida relativa de importancia de la recaudación del referido impuesto, principalmente frente al "aumento del protagonismo del sector de servicios y un mayor valor agregado en las etapas previas y posteriores a la producción" (Santi, 2019, p. 174). La confluencia de estos dos factores hizo que el gobierno recurriese a una cuestión interpretativa para expandir la base del cálculo tributario y de este modo mantener los índices de recaudación aun con la caída de la actividad económica industrial (Santi, 2019, p. 175).

Por dichos motivos concretos, el encuadramiento que haremos de la solidaridad como una práctica ligada a la propiedad no se asemeja a la utilizada en el texto. Trabajaremos una idea paralela a la presentada por Saffie, sin refutar sus argumentos sino presentando otros puntos de vista para, finalmente, defender también la idea de reciprocidad.

Como bien señala James Alm (2007), las Administraciones Fiscales alcanzan los mejores resultados cuando comprenden que en esta relación 
El papel de la solidaridad en el fundamento del Derecho Tributario: ...

fisco - contribuyente hay una diversidad de factores además de los económicos, no siendo determinantes los de orden financiero para el aumento de la evasión fiscal a niveles elevados principalmente en países con un bajo costo de cumplimiento de obligaciones tributarias (compliance fiscal).

En la empresa de Richard Bird (1992), Alm demuestra que, junto con auditorías y fiscalizaciones eficientes, la situación que ayuda a los mejores resultados en el cumplimiento de las obligaciones tributarias es la construcción de una relación de confianza con los contribuyentes, especialmente, cuando se alinean las normas tributarias con las normas sociales ${ }^{6}$.

Hay consenso en cuanto a que la falta de confianza está en la raíz de los grandes dilemas fiscales y actuales en Brasil (Coehlo, Santi, 2011). Por lo tanto, no basta comprender que la propiedad no es un derecho natural, sino entender en qué medida ella podrá ser utilizada para fines individuales y para fines colectivos, esto es, lo que el particular puede preservar en su esfera de poder y lo que puede ceder al medio social para el mantenimiento de este derecho.

Argumentaremos en este simple escrito que la solución de los problemas de legitimidad y cumplimiento de las obligaciones tributarias más allá de la idea de solidaridad también es imprescindible la ocurrencia de algunas características concretas del sistema tributario observadas en la sociedad: simplicidad y transparencia (Santi, 2019).

La constatación de tales características permite observar la idea de ciudadanía fiscal: el empoderamiento del ciudadano frente al sistema tributario, permitiéndole comprender qué, cómo, cuánto, cuándo y dónde se adeudan los impuestos, influyendo o no en su institución y, por otro lado, pudiendo, también, posicionarse contra medidas ilegales en el intento de recaudar los impuestos y exigir medidas sensibles frente a los demás particulares y en relación con los servidores públicos.

6 Un buen ejemplo es el caso de Australia. Información sobre la reforma fiscal australiana está disponibls en el sitio de Australian Taxation Office (www.ato.gov.au) y del Board of Taxation (www.taxboard.gov.au). Recomendamos la lectura de los siguientes documentos: "Improving Tax Compliance in the Cash Economy", "Developing effective compliance strategies - guide for complice offices (elaborado por el Cash Economy Task Force), "Postimplantation review into certain aspects of the consolidation regime - Discussion Paper" (elaborado por el Board of Taxation). 
Confianza y ciudadanía fiscal son, en mi opinión, los elementos claves para la solución de dichos problemas y su instrumentalización se debe a la simplicidad y transparencia de un sistema fiscal. Tales elementos son los pilares de la reciprocidad fiscal que debemos tener para eliminar los problemas de legitimidad y la falta de cumplimiento de la obligación tributaria.

\section{4. "La simplicidad es la máxima sofisticación": Magister Leonardo Da Vinci Dixit}

El valor "simplicidad" como directiva de un modelo de tributación significa sostener que la actividad recaudatoria debe ser libre de complejidad y de fácil comprensión para el contribuyente y el Estado, garantizándose la facilidad y la seguridad jurídica necesarias para el pago del tributo y el cumplimiento de las obligaciones accesorias (Santi, 2016).

La complejidad de un sistema tributario causa parálisis. No es posible saber con precisión qué tributo pagar y cuándo pagar. Solo la comprensión de la hoja de la ley libera al ciudadano de la indiferencia autoritaria. Sin la comprensión de la ley no soy libre, ni para pagar el tributo ni para no pagarlo (Rawls, 1993). Esta visión permite afirmar que la falta de comprensión de la ley incide en su sensación de inexistencia. Por lo tanto, sin la comprensión de la ley todo está permitido y nada es obligatorio (Ferraz Junior, 2012). Frente a esta paradoja tributaria ¿cómo es posible exigir la obligación tributaria?.

Es notoria la complejidad del sistema tributario brasilero (Appy, 2016), debido a varios factores, entre ellos la cantidad de tipos de normas (constitución, ley complementaria, medida provisional, ley ordinaria, decreto, ordenanza) y también por el volumen de producción de cada uno de estos tipos, sumado a la ausencia de una interpretación oficial unificada por parte del Fisco, causando aquello que Luiz Roberto Peroba denominó como avalancha de normas tributarias (2013, p. 321), con impacto directo en la cantidad de horas para cumplimiento de las obligaciones tributarias y en el volumen de litigios administrativos y judiciales. Es en esta complejidad donde reside la sensación de que las conductas no están reguladas y de que hay exceso de margen interpretativo de la ley, lo que resulta en ampliación 
El papel de la solidaridad en el fundamento del Derecho Tributario: ...

de la tributación por parte del fisco y disminución de la tributación por parte del contribuyente.

Lo que se verifica en los últimos años en Brasil no es que el contribuyente está fuera de la tributación, sino la duda sobre qué y cuánto pagar: diversos contribuyentes incluso ya aceptan el aumento de la carga tributaria si ella se presenta como definitiva y desprovista de gastos accesorios. La situación aquí, por lo tanto, no es de falta de legitimidad o incumplimiento de la obligación que se sabe con certeza que es debida, sino que se trata de una verdadera y real duda.

Sin leyes claras, objetivas y simples, ni el buen contribuyente sabe cuándo debe pagar el tributo. Sin leyes claras, objetivas y simples la autoridad tributaria vacila y pierde su principal atribución como Estado: ejercer la competencia privativa de aplicar la ley para constituir el crédito fiscal. Sin leyes claras, objetivas y simples, no hay competencia, ni autoridad.

Históricamente la tributación se basa en una idea de acuerdo por medio de una deliberación previa del órgano competente que estipula cuándo y cuánto pagará determinada comunidad y, posteriormente, controla el uso de tales recursos (Shoueri, 2017, p. 291). Como bien señala J.J. Ferreiro Lapatza "sean los propios ciudadanos a través de sus representantes quienes determinen el reparto de la carga tributaria y, en consecuencia, los impuestos que a cada uno de ellos se le pueden exigir" (1989, pp. 7-10).

Sucede que esta idea se presenta equivocada frente a un sistema complejo. La población representada no comprende lo que se deliberó y qué impuesto se debe pagar en una determinada situación de espacio y de tiempo, por lo tanto no puede controlar dicho impuesto.

Por esto la tributación necesita ser simple para ser enseñada, para ser entendida, para ser aplicada. Establecer el valor "simplicidad" como directiva de un modelo de tributación significa sostener que la actividad recaudatoria debe ser libre de complejidad y de fácil comprensión para el contribuyente. Simplicidad es la cualidad de lo que no presenta dificultad u obstáculo.

El sistema tributario dotado de simplicidad se traduce en un modelo de fácil manejo para aquellos que lo operan y tienen como objetivo cumplir el deber legal de pagar el impuesto adeudado y proporcionar las informaciones necesarias, sin obstáculos burocráticos y trampas interpretativas, 
propiciando plena comprensión al contribuyente: el contribuyente debe pagar e informar aquello que le es exigido, no cabiéndole la responsabilidad de interpretar y conocer profundamente la legislación tributaria.

La simplicidad es una virtud. Pero no es una virtud que se añada a la existencia. Es la propia existencia en la medida en que nada se añade a ella. Por esto, es la más ligera de las virtudes, la más transparente y la más escasa (Sponville, 1997, p. 163). Nada hay más simple que la simplicidad. La simplicidad no simula, no tiene artimañas, ni secretos, ni segundas intenciones. La simplicidad respeta al hombre común: es la virtud de los sabios, es la sabiduría de los santos (Sponville, 1997, p. 170).

Por eso este valor es relevante. Tenemos una línea lógica de simplicidad, comprensión, legitimidad y cumplimiento de la obligación tributaria. La "complejidad es insoportable para el ser humano" (Adeodato, 2014, p. 185), lo que se busca en todo momento como piedra de toque del derecho, para usar la feliz expresión de Celso Antônio Bandeira de Mello (2009, p. 55), es la conversión de posibilidades en probabilidades y frente a la complejidad no es posible conocer las probabilidades.

Tal simplicidad puede verificarse mediante la búsqueda de la reducción del número de impuestos, por la simplificación de la legislación y los costos burocráticos para poder pagar para la tributación (Shoueri, 2017, p. 53).

La idea de simplicidad está en el seno de la tributación. Actualmente se muestra como un gran desafío principalmente frente al modus operandi del sistema brasilero, pero sin dudas es una de las mayores sofisticaciones de una sociedad en el siglo XXI y, por lo tanto, debe ser aspirada y ser alcanzada en la mayor escala posible.

\section{Transparencia y control social de la administración tributaria. "La luz del sol es el más poderoso de todos los desinfectantes”. Louis Brandeis}

Existe la idea de que la simplificación genera transparencia. Tal situación, sin embargo, no sucede. Principalmente cuando la simplificación extiende la idea accesoria de ausencia de contacto con las autoridades fiscales, pues si la legislación es simple no es necesario "perder" horas con la burocracia 
El papel de la solidaridad en el fundamento del Derecho Tributario: ...

del fisco. Esta ausencia de contacto tiende a causar menos transparencia, situación que demuestra que las nociones de transparencia y simplicidad son complementarias y no están necesariamente implicadas (Bird, 2013, p. 184).

En el libro Kafka, Alienação e Deformidades da Legalidade contamos una historia ficticia que demuestra la crónica de la muerte anunciada del secreto fiscal en Brasil. En la historia, se relata el caso de un funcionario público al que llamo Señor "K" que posee una carrera ejemplar y siempre entendió que una operación denominada " $\mathrm{X}$ " no era pasible de tributación sobre el consumo. Del otro lado, la empresa "S" que realizó la operación "X" en los últimos cinco años ${ }^{7}$, siempre guiada por consultores técnicos, también entendió que la operación no estaba sometida a la tributación sobre el consumo.

Frente al secreto fiscal existente en Brasil, la empresa "S" no tiene acceso a los criterios normativos utilizados por el auditor "K" con respecto a las operaciones " $\mathrm{X}$ de otras empresas del mismo rubro. Frente a un cambio político en el órgano responsable con fines de aumentar la recaudación se realiza un reexamen y la posición del órgano comienza a entender que es posible considerar las operaciones " $\mathrm{X}$ " pasibles de tributación sobre el consumo. Aunque el auditor " $K$ " entiende que tales operaciones no están gravadas, reconoce que es posible una interpretación para justificar la tributación, situación que causa un dilema: (i) no gravar y ser funcionalmente responsabilizado; (ii) redactar el acta de infracción e ir en contra de su comprensión personal de la historia y la coherencia de la no tributación de esta operación determinada ${ }^{8}$.

Con base en la asimetría de información y para poder justificar este dilema es que está previsto el secreto fiscal en Brasil. La idea es la ilusión u ofuscación fiscal como estrategia para eludir los procedimientos de legi-

7 En Brasil, generalmente, el fisco posee el plazo de cinco años para examinar las operaciones y constituir el crédito fiscal contra el contribuyente. Para obtener más información sobre esta sistemática de plazo para la constitución y cobranza del crédito fiscal en el derecho brasilero consulte: Santi, E. M. D. (2011).

8 El Código Tributario Brasilero establece en el art. 100, III, con el ideal de seguridad jurídica, que son normas complementarias tributarias las prácticas observadas reiteradamente por las autoridades administrativas. 
timación y elección democrática, manteniendo al público mal informado sobre los efectos de las cargas tributarias, permitiendo el incremento financiero sin los procedimientos legales que justifican dicha conducta (Santi, 2014 , p. 400).

Si consideramos que estamos viviendo en la era de la sociedad de la información (Machlup, 1972, p. 13) y que esta es económicamente mensurable, tenemos que la información es un bien. Cuando ella se presenta en un contexto público, de informaciones financiadas por los ciudadanos, tenemos las informaciones como un bien público indisponible (Mello, 2009, p. 73). Como dice Joseph Stiglitz, las informaciones recogidas por los servidores públicos son consideradas bienes públicos, así como otros bienes usados por el gobierno, y no pueden ser, sin la debida justificación, excluidas de acceso (2013, p. 56).

Hay una dilogía entre conocimiento y secreto que afecta directamente a las sociedades democráticas contemporáneas. Uno de los pilares de base de una sociedad democrática es el derecho al conocimiento de las "actividades del gobierno y las razones por las cuales el gobierno lleva a cabo dicha actividad". Por otro lado, la idea de secreto provoca falta de confianza entre el gobierno y los gobernados (Stiglitz, 2013, p. 48). Así, con el conocimiento tenemos la democracia y con el secreto hay ausencia de democracia, de modo que no es posible sostener una tributación y una privación de la propiedad en situaciones de secreto estatales.

Esto debido a que, en este escenario, es posible aumentar la tributación en cualquier momento mediante procedimientos incorrectos para ello y que no se fundamentan en un ideal democrático de autorización y conocimiento de la tributación (no taxation without representation). Así, si el ciudadano, a través de sus representantes, no permite la institución de la tributación o su aumento y esta se lleva a cabo mediante un proceso exclusivamente interpretativo y sin la transparencia necesaria, no hay manera de justificar un ideal de solidaridad, ya que la solidaridad se basa en el conocimiento previo de las acciones que deben implementarse.

Además, el oscurecimiento de las normas (sistemas legales altamente complejos y ocultación de actos de aplicación de la ley) permite que alianzas entre elites políticas y económicas instrumentalicen el Derecho (que pierde su imperio y su autonomía en relación a la política y a la economía): 
El papel de la solidaridad en el fundamento del Derecho Tributario: ...

en otras palabras, el Derecho pasa a ser un mero instrumento utilizado por los referidos grupos para alcanzar intereses privados.

Es por esto que verificamos que una característica relevante para que un sistema tributario sea considerado bueno es la transparencia. Existe una vinculación entre el secreto y la falta de participación ciudadana. Cuando no hay transparencia falta información y esta ausencia provoca la falta de participación significativa del ciudadano en la Administración Pública Fiscal (Stiglitz, 2013, pp. 52, 57), sin la cual no hay forma de defender la solidaridad.

En esta lógica, la ley se convierte en un instrumento de formalización y mantenimiento de privilegios: agentes públicos y contribuyentes están sujetos a los intereses de los grupos dominantes, perdiendo, en vista de la complejidad del sistema, el paradigma y la garantía de la generalidad y abstracción de la ley.

En un sistema tributario transparente es posible tener características elementales para determinar la legitimidad y el cumplimiento de las obligaciones tributarias, ellas son: (i) ofrece certeza y seguridad jurídica a ambas partes del sistema tributario (Estado y contribuyente); (ii) control social sobre los actos públicos y posibilidad de verificación de las justificaciones de los posicionamientos interpretativos; (iii) evita litigios administrativos y judiciales; (iv) protege las instituciones públicas y evita el clientelismo político; (v) evita la creación de nuevas fuentes de ingresos tributarios por mera interpretación; (vi) lleva la cuestión de tributación a un debate republicano?.

La idea de transparencia, por lo tanto, está asociada directamente al control social de los actos de la Administración Pública Fiscal frente a un ideal democrático, no solo por aquellos que están directamente involucrados en la tributación o en su incremento, sino principalmente por otros agentes sociales como universidades y órganos no gubernamentales que se dedican al estudio de la tributación en su totalidad.

Cabe señalar también que la falta de transparencia de los actos y de los documentos de aplicación del derecho no solo es un obstáculo a la par-

9 Para más características relevantes véase: valorização do servidor público e o controle social do cenário da transparência fiscal. In Kafka, Alienação e deformidades da legalidade: exercício do controle social rumo à cidadania fiscal. 
ticipación, sino también un obstáculo para la innovación. Las sociedades más exitosas son aquellas capaces de responder a sus desafíos a través de la creación de nuevas formas de recombinar creencias y prácticas institucionalizadas. Para ganar la libertad de crear alternativas originales para la sociedad de modo racional y participativo se requiere tener la capacidad de maginar nuevas posibilidades y conversar sobre ellas (Santi, Correa, 2017, pp. 88-89).

Es por esto que la frase de Louis Brandeis es una directiva relevante para que el sistema tributario posibilite el equilibrio entre la propiedad y la solidaridad, pues "la luz del sol es el más poderoso de todos los desinfectantes" y esto permite una relación tributaria limpia entre el fisco y la sociedad en su conjunto.

Como afirma Richard M. Bird: "países con sistemas fiscales totalmente transparentes (en términos de conocimiento de costos y beneficios de la tributación) pueden, está claro, mejorar la estructura de sus sistemas tributarios" (2013, p. 191).

La transparencia permite al ciudadano conocer, efectivamente, con cuánto contribuye de impuestos al Estado, de modo que pueda, consciente de la carga fiscal, tomar decisiones de políticas públicas consciente democráticamente. Por otro lado, produce una relación receptiva entre fiscocontribuyente y hace que el contribuyente sepa cómo, por qué, cuánto debe pagar para cumplir con sus obligaciones tributarias.

\section{Ciudadanía fiscal. "Gobierno del pueblo, por el pueblo y para el pueblo”. Abrham Lincoln}

La relación de simplicidad y transparencia y su importancia en un contexto social como el brasilero para crear un ambiente de ciudadanía fiscal se presenta frente a los problemas que constatamos actualmente. Trabajaremos la idea del paradigma del mando/control, el problema de la falta de comprensión de la legislación, los records de recaudación frente a tal situación, el aumento exacerbado del litigio tributario para dilucidar una primera idea de ciudadanía fiscal y contextualizar la propuesta de reforma tributaria que apoyamos y que actualmente tramita en el Congreso brasilero. 
El papel de la solidaridad en el fundamento del Derecho Tributario: ...

Se denomina paradigma del mando y control a la función unilateral del fisco para calificar y castigar las conductas de los contribuyentes, situación que en Brasil terminó fomentando el maniqueísmo del fisco-institución versus contribuyente e indujo en la práctica del derecho tributario una especie de "juego del gato y del ratón" en el que estrategia y astucia se convierten en valores superiores que se sobreponen a la legalidad (Santi, 2014, p. 32).

La legalidad a la que me refiero aquí es la concreta, situada en un contexto de aplicabilidad práctica de la norma jurídica tributaria pensada por el Poder Legislativo para regular las conductas de los individuos. Como ya se mencionó, en Brasil la complejidad y falta de transparencia causan una falta de conocimiento generalizado y reafirma una constante oposición del fisco y del contribuyente.

Esta postura del fisco-institución se erige en nombre de la legítima defensa de los intereses nacionales y termina combinando el endurecimiento de la fiscalización con la flexibilización de la legalidad para preservar los niveles de recaudación (Base Erosion and Profit Shifting-BEPS): es lo que llamamos planificación tributaria a la inversa. Situación que termina castigando al buen contribuyente al mismo tiempo que incentiva al contribuyente malicioso a buscar nuevas técnicas para engañar al gobierno (Santi, 2014, 47).

Pero la sustitución del ideal de legalidad por las ideas de estrategia y astucia (vectores de una verdadera guerra) no se presentan solo en Brasil. Se trata, en realidad, de un fenómeno mundial, como lo demuestra John Braithwaite, en el que los contribuyentes que tratan de escapar a las crecientes cargas impositivas de sus países buscan vacíos legales para lidiar con la tributación reordenando las conductas dentro de la planificación tributaria (Braithwaite, 2002, p. 406).

Tenemos un verdadero laberinto impuesto por la complejidad y por la falta de transparencia (bajo la denominación de secreto fiscal). El fisco al mismo tiempo que oculta cómo interpreta y aplica la ley a casos concretos, impone al contribuyente (representado indirectamente por las empresas) el deber de interpretar ciegamente una legislación impositiva incomprensible, reforzando la idea de mando y control, pero ahora con una triste realidad: no se entiende el mandato y se es castigado por el control, debido al desconocimiento y no por la violación de mandato (Santi, 2014, p. 37). 
El modelo de mando y control es defectuoso por dos aspectos. Por un lado, es ineficiente en la misión de identificar y castigar a los infractores, ya que los contribuyentes que pretenden engañar al fisco-institución al percibir la ineficacia de las auditorias promovidas por el Estado, evaden un volumen incluso mayor de impuestos. Por otro lado, frente a este problema, el Estado se esfuerza por mantener o aumentar el nivel recaudatorio dirigiendo el poder de presunción de validez de los actos administrativos para fomentar una actividad fiscal que trabaja, sistemáticamente, "contra" el "buen contribuyente", en una lógica perversa en que el gobierno utiliza la "máquina fiscal" para recaudar y con objetivos propios, disociados de la práctica de la legalidad y sin preocuparse por el entorno empresarial, la libre competencia, la competitividad nacional e internacional de empresas (Santi, 2014, p.35).

Este escenario se contextualiza en la experticia del fisco brasilero en cobrar los impuestos. El Estado brasilero es cada vez mejor en cobrar los tributos con fundamento en un sistema cada vez peor, recibiendo el nombre de "increíble máquina de recaudar impuestos" ${ }^{10}$ principalmente frente a los sucesivos records de recaudación generados en los últimos años por el gobierno brasilero ${ }^{11}$ frente a crecimientos económicos ínfimos.

No nos parece que haya nada para celebrar en los records sucesivos de recaudación del gobierno brasilero sin conocer la consistencia de estos cargos que potencialmente solo retroalimentan la industria del litigio tributario. Los números de litigios en Brasil son completamente alarmantes. Para dar una idea, se estima que Brasil tiene R 4 billones de créditos fiscales que están en discusión judicial o administrativa (Salusse, 2018), cifra que comparada con los $\mathrm{R} \$ 6,8$ billones del Producto Interno Bruto en el año $2018^{12}$ demuestra que el crédito fiscal alcanzó un nivel cercano al $60 \%$ del PBI.

Esta situación es grave cuando se percibe que en Brasil los impuestos están concentrados en las personas jurídicas (directa o indirectamente),

${ }^{10}$ Periódico O Globo, editorial publicado el 26/01/2014. Disponible en: https://oglobo.globo.com/ opiniao/a-incrivel-maquina-de-arrecadar-impostos-11399031 > Consultado el 16/08/2019.

${ }^{11}$ Vea noticias en este sentido em: (i) < http://receita.economia.gov.br/noticias/ascom/2018/ fevereiro/receita-federal-bate-recorde-em-autuacoes-em-2017 > Consultado el 16/08/2019; (ii) < https://g1.globo.com/economia/noticia/2019/03/21/arrecadacao-tem-alta-real-de-53percent-em-fevereiro-para-r-115-bilhoes.ghtml > Consultado el 16/08/2019.

12 Fuente: https://www.ibge.gov.br/explica/pib.php 
El papel de la solidaridad en el fundamento del Derecho Tributario: ...

dejando fuera del debate sobre la tributación a las personas físicas. Sucede que no existen personas jurídicas- no tienen existencia propia ni almasiendo una ficción creada socialmente para facilitar la circulación del capital. De hecho, quien paga toda la carga impositiva es el ciudadano corporificado en la persona física. Pero esta visión no se presenta solo del lado del contribuyente, sino que también está en el concepto de Estado (o de entidad tributante). Por detrás del cargo público que integra esta entidad también hay una persona física.

Frente a dicho escenario, los elementos de simplicidad y transparencia se vuelven hacia la persona física confiriéndole poderes para participar del debate político tributario sobre qué, cómo, cuándo y cuánto tributar. Aquí es donde ingresa el concepto de ciudadano fiscal.

El concepto ciudadanía está directamente asociado con la "integración participativa en el proceso de poder", como una medida para el mejoramiento de todos los individuos que se encuentren insertos en un contexto social (Silva, 2012, p. 38). Presenta un ideario de consciencia de congruencia de la parte para con el todo.

La idea de ciudadanía como participación presupone los dos elementos que ya hemos abordado: simplicidad y transparencia. Esto porque para participar es necesario conocer primero en qué se puede participar y en segundo lugar comprender cómo se lleva a cabo esta participación. Por lo tanto, en la transparencia tenemos la posibilidad de conocimiento y en la simplicidad la posibilidad de comprensión. Cuando el individuo conoce y comprende su papel en relación con el todo, tiene la posibilidad de participar realmente de la construcción de esto pudiendo interferir y sentirse, por lo tanto, parte de él.

Es en esta línea que Walber de Moura Agra señala la idea de ciudadanía activa, clasificando un tipo de ciudadanía no solo en el poder de participar de la vida política, sino también en la posibilidad de incorporación por el ciudadano de consciencia de sus derechos y deberes sociales. En este sentido, la ciudadanía debe estructurarse para "contemplar su sentido participativo, en el que una parte significativa de las decisiones políticas pasan a ser ejercidas por el pueblo, en presupuestos participativos, asociaciones, recall (Agra, 2018, p. 121)".

Esta gradación del concepto de ciudadanía se amolda a la idea de ciudadanía fiscal. La integración participativa en el proceso de poder frente 
a la consciencia del individuo para contemplar su sentido participativo se inserta en conocer y comprender el sistema tributario para que se pueda participar de su construcción, implementación, operacionalización, y también verificar si las finalidades distributivas y de financiamiento estatal se presentan en los niveles de cantidad y de calidad esperados, construyendo así el tipo de Estado que se espera.

La idea de ciudadanía fiscal, por lo tanto, pasa por un ideal de conocimiento y comprensión del sistema tributario para que se pueda participar activamente de él y esta posibilidad participativa cause un empoderamiento del individuo que pasa a no ser más el antagonista del gobierno fiscal, sino que ahora formar parte del gobierno fiscal. La posibilidad de conocimiento genera, en este sentido, el ideal de viabilidad de conferencia de poder frente al conocimiento, que a su vez, proporciona control (Oliveira, 2011, pp. 389, 399).

La participación queda, de este modo, garantizada frente a una calificación que debe ser en todo momento deseada. Simplicidad y transparencia son, por lo tanto, elementos básicos y nucleares que garantizan la idea de ciudadanía fiscal. Como bien dice Ronald Dworkin, la ciudadanía fiscal permite un nivel democrático en el que cada uno de los miembros de la sociedad tiene la misma influencia en la legislación del país, ya sea en su producción o en su interpretación (1999, p. 436).

Tales fundamentos tienen la fuerza para rescatar la legitimidad del sistema tributario y del cumplimiento de las obligaciones tributarias.

\section{Una propuesta de reforma tributaria para el Brasil}

El sistema tributario brasilero alcanzó un grado de conflicto tan grande debido a su complejidad y distorsión de los incentivos y precios que necesita para alcanzar la idea de ciudadanía una amplia revisión (Appy, 2019b). No se trata de aumentar o reducir la carga impositiva, sino de aportar calidad al sistema tributario brasilero frente a cuatro premisas: simplicidad, transparencia, neutralidad y equidad.

Las dos primeras ya bien destacadas aquí, las dos últimas pueden ser consideradas directamente calificando la neutralidad como una forma de estructuración económica de la tributación de modo que no distorsiona 
El papel de la solidaridad en el fundamento del Derecho Tributario: ...

la organización de las empresas, la tecnología que adoptan, en general, no interfiere en las elecciones de los mercados; mientras que la equidad se presenta en la relación entre los participantes del sistema tributario como una tributación sin privilegios (Torres, 1995, pp. 287-288).

El sistema tributario brasilero no tiene ninguno de estos atributos. No es simple ni transparente. Por no respetar el principio de equidad, es regresivo, sobrecargando más a la porción más pobre de la población que a las familias de mayor renta. Por no ser neutro, es extremadamente ineficiente, perjudicando de sobremanera el crecimiento del país.

Fue frente a estas constataciones que el Centro de Ciudadanía Fiscal (CCiF) desarrolló, en los últimos años, una propuesta integral de reforma impositiva sobre el consumo. Estas ideas fueron materializadas en la Propuesta de Enmienda Constitucional no 45, de 2019 (PEC 45) ${ }^{13}$ que actualmente se encuentra en proceso en el Congreso Nacional y que ha tomado lugar como una de las propuestas más debatidas.

El foco en el consumo se presentó frente al consenso de que este segmento de la tributación es altamente problemático y explica una parte importante de las distorsiones de nuestro sistema tributario, especialmente por su impacto negativo sobre la productividad y el crecimiento.

Una parte relevante de estos problemas es de naturaleza estructural y está relacionada con la fragmentación de la base de incidencia del consumo en cinco tributos, generados por tres esferas distintas de gobierno (Unión, Estados y Municipios). Esta clasificación de impuestos y repartición de competencias previstas inicialmente en la Constitución, resulta en una infinidad de legislaciones de institución y reglamentación emitidas por las tres esferas de gobierno. Además, cada ente federativo creó sus propios beneficios fiscales, que se dividen en institutos con nombres de regímenes especiales, exenciones, reducciones en las bases impositivas y alícuotas diferenciadas ${ }^{14}$.

Otras distorsiones proceden de las características de cada uno de los impuestos sobre el consumo, como los impuestos sobre bienes y servicios

${ }^{13}$ En Brasil la tributación tiene uma larga y descriptiva regulación constitucional.

${ }^{14}$ Esta cantidad de impuestos y de regímenes especiales proovoca una dificultad binaria: el contribuyente para cumplir con las obligaciones tributarias y el fisco para fiscalizar y señalar la corrección de los comportamientos. 
de comunicación que se originan en operaciones interestatales (base de la guerra fiscal existente en Brasil), la incidencia acumulada de impuestos exclusivos sobre los servicios y sobre parte de los ingresos, las restricciones crediticias sobre impuestos no acumulativos y la dificultad de recuperación de los créditos no acumulados.

La base de la propuesta del CCiF es la sustitución de los cinco impuestos actuales por un único impuesto sobre bienes y servicios (IBS), que tiene las características de los mejores IVAs del mundo ${ }^{15}$, en particular la adopción de una alícuota uniforme para todos los bienes y servicios, transición de un modelo de tributación gradual (diez años), cobranza en el destino (para operaciones interestatales) y centralizada y generada de forma coordenada por representantes de los tres entes, con único cobro mensual, con distribución de la recaudación automática a través de un comité gestor, con gobernanza paritaria. El Estado y Municipio de destino serán los titulares del impuesto (no hay guerra fiscal).

La alícuota es el punto clave de la propuesta y consistirá en la suma de otras tres alícuotas instituidas por cada uno de los entes de la federación, siendo el impuesto distribuido proporcionalmente a la incidencia de la alícuota sobre el consumo de cada una de ellas, los cuales también tienen competencias para fijarlas. Durante el periodo de transición serán calculadas las alícuotas de referencia, pudiendo cada uno de los entes aumentar o disminuir su alícuota frente a tal referencia, manteniendo la uniformidad sobre bienes y servicios, con total preservación de la autonomía.

Dado que el IBS es un impuesto sobre el consumo, la elevación o reducción de la alícuota implica sobrecargar más o menos a los consumidores del propio estado o municipio, creando un escenario de responsabilidad política en el que se contraponen de forma transparente el poder público y los ciudadanos- consumidores- electores.

${ }^{15}$ El IVA es un impuesto no acumulativo, que se cobra a lo largo de la cadena de producción y comercialización. En cada etapa, se recoge la diferencia entre el impuesto sobre las ventas (débito) y el impuesto sobre los insumos utilizados (crédito). Las características de um buen IVA son conocidas: incidencia sobre una base amplia (bienes, servicios e intangibles) de la tributación en destino, alícuota uniforma (sin excepciones), adopción plena de la no acumulación, exención de las inversiones y de las exportaciones y devolución de los créditos acumulados. 
El papel de la solidaridad en el fundamento del Derecho Tributario: ...

Las características de esta propuesta posibilitan los valores de la simplicidad, transparencia, neutralidad y equidad. Dichos valores alteran la forma de poder del Estado para el ciudadano, propiciándole información y conocimiento, elementos que posibilitan la participación en el proceso de institución y aplicación impositiva, justificando la figura de ciudadanía fiscal.

\section{De solidaridad (antigua narrativa) para reciprocidad (nueva narrativa para guiar los espíritus de los presentes)}

Señalaremos brevemente la necesaria e importante alteración del concepto de solidaridad al concepto de reciprocidad en materia impositiva.

Es posible percibir un cambio de paradigma en las narrativas y en los intercambios de valor en la sociedad. Si antes la generación de riqueza sucedía en el aislamiento de propiedad, en la cual su individualización era considerada relevante, actualmente el valor está en el compartir. Este escenario es claro en el deterioro de las bases impositivas de las industrias, por ejemplo, y en la evolución de los servicios digitales, en la inteligencia artificial.

El paradigma anterior se basaba en juegos de suma cero, es decir, la ganancia de un jugador representa necesariamente la pérdida de otro. Hoy, el cambio de paradigma está en el cambio de los juegos de todos ganan (win-win), en el cual los participantes tienen ganancias recíprocas y cooperativas: juegos de suma no cero.

La idea de solidaridad está asociada a una postura pasiva. De dependencia mutua que se establece entre dos o más personas (Freire, 1954). Cuando soy solidario no necesariamente estoy comprometido con esa cuestión de solidaridad. Por ejemplo, cuando veo una persona en la calle puedo ser solidario con el estado de vida de ella, lamento dicho estado y espero que consiga una mejora, pero no necesito tomar medidas para que esto suceda. La solidaridad es unilateral y estática, no exige una acción.

Por otra lado, la reciprocidad, implica dar y recibir, una situación de compromiso con el todo. No es suficiente solo sentir, sino también tener una iniciativa de participación ${ }^{16}$. En este sentido, tenemos la idea de compartir

${ }^{16}$ Vea el discurso de de Reinaldo Popo Pamponet en: https://youtu.be/SwyHgp_FT9A 
(Freire, 1954). Implica dar, recibir y nutrir el sistema en su conjunto, construyendo una relación de responsabilidad y representatividad del individuo con el colectivo. La reciprocidad es bilateral y dinámica, requiere compromiso.

Con respecto al sistema tributario, es necesario que los individuos tengan, como señala Saffie, un reconocimiento recíproco. El individuo necesita ver el reflejo de sí mismo en el entorno social que vive, participando, comprometiéndose y contribuyendo a ese entorno, ya que cada vez que actúa de esta manera estará participando y reconociendo su representatividad y responsabilidad.

En materia impositiva, la simplicidad y la transparencia hacen posible esta reciprocidad, ya que permiten que el individuo comprenda y reconozca su papel como ciudadano fiscal, percibiendo la interrelación entre él y el colectivo, situación que en teoría ayuda en la solución de los problemas de legitimidad y aplicación del derecho tributario.

\section{Diez conclusiones institucionales}

C1. El problema enfrentado: Según Saffie, la noción económica neoliberal causa dos problemas, la ilegitimidad del Derecho Tributario y la aplicación de estrategias de evasión y elusión tributarias practicadas por los contribuyentes. El primer problema se basa en la falta de retribución (pago del impuesto y falta de contraprestación pública) y el segundo, como consecuencia del primero, impacta en la recaudación. Ambas situaciones están planteadas en una noción de propiedad como derecho natural.

C2. Solución propuesta: Saffie argumenta que ambos problemas pueden resolverse mediante una noción de solidaridad que atraviesa al individuo que se encuentra inserto en la sociedad. Los sistemas tributarios pueden considerarse como una de las prácticas dentro de las cuales se puede aprender sobre la virtud de la dependencia mutua. La propiedad privada y los impuestos son conceptos inseparables, dos caras de una misma moneda, ya que estos son los medios para subsidiar al Estado, el que a su vez garantiza el espacio de libertad y propiedad para todos. 
El papel de la solidaridad en el fundamento del Derecho Tributario: ...

C3. Especificidades de Brasil: los desafíos de Brasil preceden a una noción de solidaridad como justificación de la tributación para garantizar la propiedad. Tenemos un sistema tributario hipercomplejo; malversación de los gastos públicos; ineficiencia administrativa y falta de prestación de servicios básicos como educación, salud y seguridad, todo esto en un contexto de migración de las funciones básicas del Estado hacia el sector privado.

C4. Elementos de una solidaridad concreta: ante problemas diversos se requieren soluciones diversas, la recuperación de la armonía de la relación fisco-contribuyente, con la generación de confianza, responsabilidad y un mejor entorno empresarial, se basa en la simplicidad, la transparencia y la ciudadanía fiscal, elementos orientadores de la PEC 45 que pretende reformular el modelo de tributación de consumo en Brasil.

C5. Simplicidad como posibilidad de comprensión: la tributación necesita ser simple para ser enseñada, para ser entendida, para ser aplicada. Establecer el valor "simplicidad" como directiva de un modelo de tributación significa sostener que la actividad recaudatoria debe ser libre de complejidad y de fácil comprensión al contribuyente. Simplicidad es la cualidad de que no presenta dificultad u obstáculo.

C6. Transparencia como acceso a la información: la transparencia permite al individuo conocer, efectivamente, con cuánto y cómo contribuye tributariamente con el Estado, de modo que pueda, consciente de la carga tributaria, tomar decisiones de políticas públicas consciente democráticamente. Por otro lado, brinda una relación sensible entre fisco - contribuyente y hace que este sepa cómo, por qué, cuánto y cuándo pagar para cumplir con sus obligaciones tributarias.

C7. Ciudadanía como participación: simplicidad y transparencia permiten la ciudadanía fiscal, así como la posibilidad formal y material de participación ciudadana en las elecciones políticas, no solo recibiendo todas las informaciones necesarias para ello y asegurando el ejercicio de influir en la toma de decisiones de manera formal (procedimientos iniciados para 
esto), como también tener una calidad en esta participación, que podemos llamar una ciudadanía activa.

C8. Rescate del ciudadano para el debate tributario: la idea de ciudadanía se basa en la posibilidad de participación y el escenario actualmente existente en Brasil no favorece tal situación, ya que la tributación es indirecta y excesivamente concentrada en la persona jurídica, de modo que el individuo, quien verdaderamente paga los impuestos, queda fuera del debate sobre tributación.

C9. Reformar para avanzar: es frente a las referidas ideas que se fundamenta la propuesta de reforma tributaria presentada por el CCiF y que está establecida en la PEC 45 que está en proceso actualmente en el Congreso Nacional. Se busca con ella la unificación de cinco impuestos en uno, valiéndose de cuatro ideas básicas: simplicidad, transparencia, neutralidad e isonomía. El objetivo de esta propuesta es mejorar el entorno empresarial y llevar al ciudadano de regreso al debate sobre el financiamiento de los gastos públicos y, en consecuencia, de la calidad de los gastos públicos.

C10. De la solidaridad a la reciprocidad: la migración de la idea de solidaridad a la de reciprocidad implica el compromiso necesario del individuo con la noción de colectividad que quiere construir y esto implica reconocer cuál será el esfuerzo de cada ciudadano. La simplicidad y la transparencia permiten el acceso a la información y su comprensión, generando la figura del ciudadano fiscal, participante de las políticas públicas. Esta participación incluye dar, recibir y nutrir, lo que implica el reconocimiento individual con el todo y la posibilidad de superación del problema de legitimidad y aplicación del derecho tributario.

\section{Bibliografía}

Adeodato, J. M. (2014). Uma teoria retórica da norma jurídica e do direito subjetivo. São Paulo: Noeses. 
El papel de la solidaridad en el fundamento del Derecho Tributario: ...

Agra, W. M. (2018). Comentários à Constituição do Brasil. En Canotilho, J. J. G. et al. (coord). 2. ed. São Paulo: Saraiva Educação.

Araújo, P. B. (1954). O impôsto sôbre a transmissão da propriedade. Rio de Janeiro: Fundação Getúlio Vargas.

Alm, J; Vazquez, J. M. (2007). Tax Morale and evasion in Latin América. Working Paper 07-04. Georgia State University. Dispoinível em: < https://icepp.gsu.edu/files/2015/03/ispwp0732.pdf > Acesso em 09.08.2011.

Appy, B. et al (2019a). Tributação no Brasil: o que está errado e o que concertar. Disponível em: <http://www.ccif.com.br/wp-content/ uploads/2018/07/Diretores_CCiF_Reforma_Tributaria_201802-1.pdf> Acesso em 06/08/2019.

Appy, B. (2016). Por que o sistema tributário brasileiro precisa ser reformado. Disponível em <http://www.ccif.com.br/wp-content/ uploads/2018/07/Appy_Tributa\%C3\%A7\%C3\%A3o_1610.pdf> Acesso em 13/08/2019.

Appy, B. Et al. (2019b). Por uma nova arquitetura tributária. Folha de São Paulo. Caderno Ilustríssima.

Bird, R. (2013). Transparência e tributação: algumas reflexões preliminares. In Transparência fiscal e desenvolvimento: homenagem ao professor Isaias Coelho. SantiN, E. M. D. et al (coord). São Paulo: Fisosoft.

Bird, R; Jantscher, M. C. (org.). (1992). Improving tax administration in developing countries. Washington, D.C.: International Monetary Fund.

Braithwaite, J. (2002). Rules and Principles: A Theory of Legal Certainty. Australian Journal of Legal Philosophy, vol. 27.

Coelho, I. e Santi, E. M. D. (org.). (2011). Reforma Tributária viável: simplificação, transparência e eficiência. São Paulo: Quartier Latin.

Dworkin, Ronald. (1999). O império do direito. São Paulo: Martins Fontes.

Ferraz Junior, T. S. (2012). Unanimidade ou maioria nas deliberações do Confaz - Considerações sobre o tema a partir do princípio federativo. Revista Fórum de Direito Tributário.

Freire, L. (1954). Grande e novíssimo dicionário da língua portuguesa. Vol. V. 2 ed. Rio de Janeiro: José Olympio Editora. 
Jamur, M. (2005). Solidariedade: uma noção tensionada entre o público e o privado. Revista da Administração Pública, V. 39, n. 3. Rio de Janeiro: Fundação Getúlio Vargas.

Pereira, Virgilio de Sá. (2007). Manual do Código Civil Brasileiro: direito das coisas da propriedade. Paulo Lacerda (coord). Rio de Janeiro: Forense.

Lapatza, J.J. F. (1989). Principio de legalidad y la reserva de ley. Revista de Direito Tributário (XXXIII). São Paulo: RT.

Machlup, F. (1972). The production and distribution of knowledge in the United States. Princeton: Princeton University press.

Mendes, G. F. (2018). Curso de Direito Constitucional. 13. ed. São Paulo: Saraiva Educação.

Mello, C. A. B. (2009). Curso de Direito Administrativo. 26. ed. São Paulo: Malheiros.

Nabais, J. C. ( 2015). O Dever Fundamental de Pagar Impostos: contributo para a compreensão constitucional do estado fiscal contemporâneo. Coimbra: Almedina.

Oliveira, J. M. (2011). A relação entre educação, transparência, democracia e qualidade da tributação. In Tributação e Desenvolvimento: homenagem ao Prof. Aires Barreto. Santi, E. M. D. (coord.). São Paulo: Quartier Latin.

Peroba, L. R. (2013). Transparência e Relação entre Fisco e Contribuinte. Santi, Eurico Marco Diniz de et al (coord). Transparência Fiscal e Desenvolvimento. São Paulo: Fiscosoft Editora.

Rawls, J. (1993). Uma teoria de justiça. Portugal: Editorial Presença.

Salusse, E. (2018). O Brasil tem R $\$ 4$ trilhões de créditos tributários a recuperar. Valor económico. Disponível em: <https://www.valor.com. br/legislacao/fio-da-meada/5314673/o-brasil-tem-r-4-trilhoes-decreditos-tributarios-recuperar $>$ Acesso em 16.08.2019.

Santi, E. M. D. (2014). Kafka, Alienação e deformidades da legalidade: exercício do controle social rumo à cidadania fiscal. Fiscosoft Editora e Revista dos Tribunais.

, E. M. D. et al. (2019). Valor Tributável mínimo e imposto sobre produtos industrializados: evolução histórica da legislação abstrata e prática. Max limonad: São Paulo. 
El papel de la solidaridad en el fundamento del Derecho Tributario: ...

E. M. D. (2018). Sete diretivas para uma reforma de qualidade do sistema tributário em 2019. Jota. Disponível em: <https://www. jota.info/opiniao-e-analise/artigos/sete-diretivas-reforma-sistematributario-2019-31072018\#_ftn11> Acesso em 06/08/2019.

E. M. D. (2016). Novo ICMS do Mato Grosso: a simplicidade é a maior das sofisticações. Jota. Disponível em: <https://www.jota.info/ opiniao-e-analise/artigos/novo-icms-mato-grosso-simplicidade-emaior-das-sofisticacoes-21112016> Acesso em 07/08/2019.

, E. M. D. e Corrêa, A. R. (2017). (In)visibilidade institucional e transparência como estratégias de valorização da atividade tributária: que Receita Federal queremos em 2018, no seu aniversário de 50 anos?. São Paulo: Max Limonad.

, E. M. D. (2011). Decadência e Prescrição no Direito Tributário. 4. ed. São Paulo: Saraiva.

, E. M. D. (2015). Arquitetura da destruição: o ICMS e seus 8.709.120 sistemas. Jota. Disponível em: <https://www.jota.info/ opiniao-e-analise/artigos/arquitetura-da-destruicao-o-icms-e-seus-8709-120-sistemas-24062015> Acesso em 6/08/2019.

Shoueri, L. E. (2017). Direito Tributário. 7 ed. São Paulo: Saraiva.

Silva, J. A. (2012). Comentário contextual à constituição. 8. ed. São Paulo: Malheiros.

Sponville, A. C. (1997). Pequeno tratado de grandes virtudes. São Paulo: Martins Fontes.

Stiglitz, J. (2013). Sobre a liberdade, o Direito de Conhecer e o Discurso Público. In Transparência fiscal e desenvolvimento: homenagem ao professor Isaias Coelho. Santi, E. M. D. et al (coord). São Paulo: Fisosoft. Torres, R. L. (1995). Os direitos humanos e a tributação: imunidades e isonomia. Rio de Janeiro: Renovar. 